\title{
Application of Palliative Care in Improving the Quality of Life of Patients with Cancer Pain
}

\author{
Zuyan Fan, Jinxiang Lin*, Xiangwei Chen, Xiuyan Huang \\ Department of Medical Oncology, the Third Affiliated Hospital of Sun Yat-Sen University, Guangzhou, China \\ Email: zy.fan@163.com, ${ }^{\star} 13247389981 @ 163 . c o m, 410845059 @ q q . c o m, 312709553 @ q q . c o m$
}

How to cite this paper: Fan, Z.Y., Lin, J.X., Chen, X.W. and Huang, X.Y. (2017) Application of Palliative Care in Improving the Quality of Life of Patients with Cancer Pain. Open Journal of Nursing, 7, 473-480. https://doi.org/10.4236/ojn.2017.74037

Received: February 23, 2017

Accepted: April 18, 2017

Published: April 21, 2017

Copyright $\odot 2017$ by authors and Scientific Research Publishing Inc. This work is licensed under the Creative Commons Attribution International License (CC BY 4.0).

http://creativecommons.org/licenses/by/4.0/

\begin{abstract}
Objective: To explore the effect of palliative care on the quality of life of patients with cancer pain. Methods: For May 2015 to May 2016 hospitalized 57 patients with advanced cancer pain carry out palliative care. At the same time, the quality of life questionnaire, including physical function, role function, emotional function, cognitive function and social function, were investigated at the time of admission and 6 weeks after admission. Results: Patients with various functions have significantly improved after palliative care $(\mathrm{P}<0.05)$. Conclusions: Palliative care can effectively improve the quality of life of patients with cancer pain. It is worth in clinical promotion.
\end{abstract}

\section{Keywords}

Cancer Pain, Palliative Care, Quality of Life, Nurse

\section{Introduction}

Cancer pain is a common symptom in cancer patients [1] [2] [3], more than $50 \%$ of cancer patients have pain, of which $30 \%$ of intolerable severe pain [4], seriously affect the quality of life of patients, and easy to make patients lose the courage and confidence of life. Palliative care is an active, holistic approach to care for patients with incurable diseases. The main approach is to control pain and other symptoms, manage mental, social, and spiritual problems, and improve the lives of patients and their families Quality [5]. The department from May 2015 to May 2016 for 57 patients with cancer pain in patients with palliative care, and achieved good results, the report is as follows.

\section{Materials and Methods}

\subsection{Study Design}

This study adopted a quasi-experimental one-group pretest/posttest design and a 
convenience sampling method. Study participants, who were first admitted to the hospital for cancer patients with pain, participated in a 6-week palliative care in this study.

\subsection{Participants and Setting}

Participants were recruited between May 2015 and May 2016 a total of 60 hospitalized patients, The inclusion criteria were as follows: 1) Initial diagnosis of advanced cancer patients and first admitted to the hospital, admission pain score of 5 - 10 points; 2) Use of oral opioid or analgesic Oxy Contin for titration after admission, the titration success, pain score control in 3 points or less; 3) Informed and consent to participate voluntarily. Exclusion criteria: 1) Patients with non-cancer pain; 2) Titration is not successful, pain score control in more than 3 points; 3) Cannot cooperate with the investigation of patients.

The initial recruited 60 cancer patients with pain accepted the invitation; however, after 2- 4 weeks, three patients left the program. The reason of withdrawal from the study was death. In addition, because the patient source is less, and in order to reduce the study of the interference factors, strictly set the inclusion criteria and exclusion criteria, causing a small sample size in this study. Finally, only 57 patients completed the study.

\subsection{Palliative Care Method}

\subsubsection{Provide a Good Ward Environment}

Nurses should pay attention to the ward environment, keep the room fresh air. Arrange the ward according to the severity of the patient's condition, such as: the disease phase, or in accordance with the wishes of patients choose a single room to facilitate family members. For stable and more susceptible to disturbed patients may be appropriate to reduce the night patrol, try to remove the factors that cause discomfort.

\subsubsection{Life and Nutritional Care}

patients with advanced cancer have varying degrees of malnutrition, encourage patients to eat high-calorie, high protein, high vitamin, digestible food, according to the patient preferences, do not stress taboos, wards prepared microwave oven to facilitate patients at any time snacks. For patients who cannot eat, should be prescribed to enteral nutrition or intravenous nutrition therapy.

\subsubsection{Psychological Care}

Palliative care is to help patients with a positive attitude as possible to face life. Nurses should promptly detect and deal with the psychological problems of patients, and family members to support patients with the correct face of the disease, maintain an optimistic attitude.

\subsubsection{Pain Treatment and Care}

1) Church of patients with mild pain relief of common methods such as deep breathing, rhythmic massage, relaxation, to participate in activities, music and rehabilitation exercises; psychological suggestion such as words suggestive, drug 
suggestion, sedative, hypnotic and so on. 2) Respect the patient's response to pain: focus on language and physical communication with the patient, to prevent improper language on the psychological harm caused by patients. Often accompanied by the patient, listen to the voices and needs of patients, to create a warm and appropriate ward environment, as much as possible to meet the needs of patients in all aspects. 3) To promote patient comfort measures: to avoid constipation, can eat crude fiber, nutrient-rich food. Once the nausea, vomiting, constipation, etc., adverse reactions to timely and effective treatment. 4) Pain assessment standardization, assessment of nurses and doctors in a timely manner, according to the patient's pain and changes in condition, timely adjustment of drug dose (dose titration), or change the way of pain, if necessary, use analgesia pump. At the same time, assess the family members and relatives of patients with pain treatment knowledge, attitude and role in the treatment to understand their difficulties. 5) To strengthen the education of nurses, to avoid the behavior of non-timely medication, to pain medication as far as possible to do medication to the mouth. Close observation of the use of analgesics adverse reactions, asked whether the patient because of adverse reactions to self-decrement or refusal of medication behavior. Strengthen the education of patients and their families, to avoid leakage medication, not on time medication, selfdecrement or withdrawal behavior. Informing patients and their families of the common cause of outbreaks of pain are changes in position, activities, meals, etc., at the same time, to help patients find as much as possible to control the incentive for the outbreak of pain caused by the method. If the patient due to examination, fasting and other reasons not to take medicine on time, nurses should promptly contact the doctor, according to the disease to give other ways of pain medication.

\subsubsection{Respect the Patient's Right to Know and Privacy}

Nurses and family members first unanimous, and patients or families to discuss care plans and measures, patients can choose to accept or refuse care. In the nursing process, the privacy of patients is protected.

\subsubsection{Death Intervention}

Understanding of life, respect for life, enhance the value of life, the death of patients education, so that patients understand the Western culture to treat the death of the basic views and attitudes. Patients with advanced cancer are no longer satisfied with how to prolong life, no longer pray for too much treatment, more is to consider how to alleviate the pain. First, patients create a family-style ward environment, respect for the wishes of patients and families, concerned about and meet the patient's personality, dignity, allowing patients to retain their lifestyle, To take active palliative and supportive therapy, control symptoms, eliminate pain, get rid of the fear of death and anxiety of patients, to understand the death is the objective law of life. Only know about death, a correct understanding of death can be a positive view of life, aware of the meaning of life, bearing the responsibility of survival. 


\subsection{Instruments}

The study tools comprised a structured questionnaire designed in this study, including basic information, disease characteristics, the quality of life Checklist EORTC QLQ-C30 [6].

Basic Information: The basic information obtained was age, height, Gender, religion, marital status, education level, economical status.

Disease characteristics: Diagnosed disease, pain score, pain treatment.

EORTC QLQ-C30: The scale includes 30 entries, including 1 overall quality of life scale and 5 functional scales, that is, physical function, role function, emotional function, cognitive function, social function, The scale score of 0 to 100 points, the higher the score that the better the function, the higher the quality of life.

Study Tools and Tests of Reliability and Validity: The scales adopted in this study were widely used domestic and international scales, all of which exhibit good reliability. In this study, EORTC QLQ-C30 was 0.85 .

\subsection{Ethical Considerations}

This study was approved by the institutional review board of the hospital where the study was conducted. The purpose and process were explained to the participants, and after signing an informed consent form, they were enrolled in the study. In addition, participants were informed that they could withdraw from the study at any time without a loss of benefits. The patients were assured that involvement in the study would not affect their medical care and that all information obtained from the questionnaire would be treated confidentially and used only for research purposes.

\subsection{Data Collection Procedure}

Investigation method Interview of basic information and disease characteristics, Quality of life investigation, using EORTC QLQ-C30, respectively interview, on admission and 6 weeks after admission of patients with quality of life score comparison.

\subsection{Data Analysis}

SPSS version 19.0 was used to analyze data and significant level was set as 0.05 (SPSS, Chicago, IL, USA). Participants' basic information was exhibited according to frequency, percentage, mean, and standard deviation (SD).

\section{Results}

\subsection{Basic Information and Disease Characteristics of Participants}

The basic information of study participants is shown in Table 1; and the disease characteristics of participants are shown in Table 2.

\subsection{The Quality of Life of Participants}

The quality of life score before and after the palliative care was significant dif- 
ference $(P<0.05)$, the score of 5 functions and overall quality of life shown in Table 3.

\section{Discussion}

Quality of life is an individual in the social and daily activities of the functional power and subjective feelings, is biological, medical and social psychological

Table 1. Basic information of participants $(\mathrm{N}=57)$.

\begin{tabular}{|c|c|c|c|c|}
\hline Characteristics & Categories & $\mathrm{n}$ & $\%$ & \\
\hline \multirow[t]{5}{*}{ Age $(\mathrm{N}=57)$} & & & & $\mathrm{M} \pm \mathrm{SD} 50.16 \pm 14.19$ \\
\hline & $25 \sim 40$ & 18 & 31.58 & \\
\hline & $41 \sim 60$ & 26 & 45.61 & \\
\hline & $61 \sim 80$ & 10 & 17.54 & \\
\hline & $>80$ & 3 & 5.26 & \\
\hline \multirow[t]{2}{*}{ Gender } & Male & 37 & 64.91 & \\
\hline & Female & 20 & 35.09 & \\
\hline \multirow[t]{3}{*}{ Religion } & Christianity & 2 & 3.51 & \\
\hline & Buddhism & 9 & 15.79 & \\
\hline & None & 46 & 80.7 & \\
\hline \multirow[t]{3}{*}{ Marital status } & married & 37 & 64.91 & \\
\hline & Not-married & 16 & 28.07 & \\
\hline & Widowed & 4 & 7.02 & \\
\hline \multirow[t]{4}{*}{ Education level } & Elementary & 3 & 5.26 & \\
\hline & Middle & 18 & 31.58 & \\
\hline & Senior & 21 & 36.84 & \\
\hline & University & 15 & 26.32 & \\
\hline \multirow[t]{3}{*}{ Economical status } & High & 17 & 29.82 & \\
\hline & Middle & 36 & 63.16 & \\
\hline & Low & 4 & 7.02 & \\
\hline
\end{tabular}

Table 2. Disease characteristics of participants $(\mathrm{N}=57)$.

\begin{tabular}{cccc}
\hline Characteristics & Categories & $\mathrm{n}$ & $\%$ \\
\hline \multirow{2}{*}{ Diagnosed disease } & gastric cancer & 8 & 14.03 \\
& liver cancer & 3 & 5.26 \\
breast cancer & 5 & 8.77 \\
& colon cancer & 12 & 21.05 \\
& esophageal cancer & 2 & 3.51 \\
& pancreatic cancer & 7 & 12.28 \\
& prostate cancer & 5 & 8.77 \\
& ovarian cancer & 7 & 12.28 \\
& lung cancer & 8 & 14.04 \\
Pain score(on admission) & 5 - 7 & 39 & 68.42 \\
& 7 - 10 & 18 & 31.58 \\
Pain treatment & Oral morphine tablets & 52 & 91.23 \\
& TTS-Fentanyl & 5 & 8.77 \\
\hline
\end{tabular}


Table 3. Comparison of quality of life scores before and after palliative care scores, $\mathrm{x} \pm \mathrm{s}$.

\begin{tabular}{ccccc}
\hline \multirow{2}{*}{ The category of function } & \multicolumn{4}{c}{ Dimensions and subscales } \\
\cline { 2 - 5 } & On admission & After 6 weeks & t-value & P-value \\
\hline body function & $61.23 \pm 6.31$ & $68.53 \pm 4.75$ & -13.50 & 0.000 \\
role function & $59.03 \pm 4.68$ & $65.20 \pm 4.50$ & -14.66 & 0.000 \\
emotional function & $59.56 \pm 4.74$ & $69.27 \pm 2.82$ & -16.65 & 0.000 \\
cognitive unction & $50.60 \pm 2.51$ & $59.20 \pm 3.19$ & -19.74 & 0.000 \\
social function & $61.56 \pm 2.94$ & $68.07 \pm 2.94$ & -10.65 & 0.000 \\
overall quality of life & $61.06 \pm 2.49$ & $67.57 \pm 3.84$ & -13.81 & 0.000 \\
\hline
\end{tabular}

collection concept [7]. The cancer pain as a tumor patient's fifth vital signs, both physical and psychological, will be deeply troubled by the patient, which seriously affects the quality of life of patients.

Palliative care in developed countries has formed a more complete system [8]. In this study, palliative care was used in the care of cancer pain patients, strengthen the nutritional intervention of patients, psychological care and humanistic concern, attention to the control of pain and complications of treatment, attention to the death education for patients and their families. Tumor is a highconsumption disease, pain treatment can also cause gastrointestinal reactions, therefore, cancer pain patients usually malnutrition. In the process of palliative care, through nutritional evaluation and intervention care, to improve the nutritional status of patients, reducing the patient malnutrition caused by fatigue, edema, and thus improve the patient's body function $(\mathrm{T}=-13.50, \mathrm{P}=0.000)$; When patients know that they are diagnosed with cancer, they often produce a series of psychological reactions, and because of painful torture, the patient is more likely to produce anxiety, fear of emotions. In this study, through the effective control of pain, attention to psychological care and humanistic concern, to reduce the patient's negative emotions, increased confidence in life, so that the patient's emotional function improved $(\mathrm{t}=-16.64, \mathrm{P}=0.000)$; Any social role needs to have a process of adaptation, the patient role is no exception. Through the communication with the patient, respect for the patient's right to informed consent, and with the patient to develop care plans and care measures, thus improving the patient's treatment and care compliance, so that patients more easily adapt to the patient's role function $(t=-14.66, \mathrm{P}=0.000)$; Studies have shown that: nurses on cancer patients with pain management education is more conducive to the patient to reduce the pain and pain medication use obstacles, improve the effectiveness of cancer pain management [9], In this study, in addition to active treatment of pain, but also to strengthen the nurses, patients and their families on the pain-related knowledge of education, improve the patient's cognitive function $(t=-17.74, \mathrm{P}=0.000)$; In the process of palliative care, death education is strengthened, so that patients and their families establish the correct attitude and cognition of death, take a positive attitude to live and improve the social function of patients $(t=-10.65, \mathrm{P}=0.000)$; All in all, after a se- 
ries of palliative care, the patient was fully cared for from the body and mind, improving the overall quality of life of the patient $(t=-13.81, P=0.000)$. All in all, after a series of palliative care, the patient was fully cared for from the body and mind, improving the overall quality of life of the patient $(\mathrm{t}=-13.81, \mathrm{P}=$ $0.000)$

In summary, palliative care to improve the quality of life of cancer pain patients have a role, it is worth in clinical application. Nurses should strengthen the professional training and education of palliative care, learn from foreign successful experience, take the initiative to cooperate with doctors, and provide relevant objective symptom assessment and patient subjective assessment, to strengthen disease-related knowledge education, palliative care applied to cancer patients Care, to better improve the quality of life of patients.

\section{Conclusion}

The results of this study show that palliative care can improve the quality of life of cancer patients. However, the results of this study are limited by the single-group pretest/posttest design, a study length of only 6 weeks, and a small sample size; therefore, the results should be generalized with caution. In addition, palliative care is still at the beginning of the country, it involves patients, families, all aspects of society, but also involves science and culture, ideology, economy, law and other fields, we need further exploration and practice. Therefore, recruiting more cancer pain patients, increasing the number of samples, further research that adopts a quasi-experimental design and involves a control group to enable comparing the effectiveness, to improve the generalizability of the results is necessary.

\section{Acknowledgements}

I hereby, thank all the patients and their families who participate in this research for their cooperation.

\section{References}

[1] Weng, G.Z., Liu, L.N. and Huang, Y.Y. (2012) Nursing Management of Day Ward in Cancer Internal Medicine. Journal of Nursing Science, 27, 53-54. (in Chinese)

[2] Silver, J. and Mayer, R.S. (2007) Barriers to Pain Management in the Rehabilitation of the Surgical Oncology Patient. Journal of Surgical Oncology, 95, 427-435. https://doi.org/10.1002/jso.20780

[3] Li, Y.L. and Zeng, P. (2005) New Ideas of Cancer Pain Drug Treatment. Herald of Medicine, 24, 1070-1071. (in Chinese)

[4] Huang, X.J., Wang, C.H. and Yang, H.B. 2004 1999-2004 Application of Narcotic Analgesics. Herald of Medicine, 23, 269-270. (in Chinese)

[5] Dai, H.X. (2002) Palliative Care New Nursing Methods. Journal of Nurses Training, 17, 103-104. (in Chinese)

[6] Wang, J.P., Chen, Z.G., Lin, W.J., et al. (2000) Chinese Cancer Patients to Determine the Quality of Life-EORTC QLQ-C30 Trial in China. Acta Psychologica Sinica, 32, 438-442. (in Chinese) 
[7] Zhu, M.L., Zheng, X.X., Liang, P., et al. (2008) Ovarian Cancer Survivors of Life Quality and Related Factors of the Investigation and Study. Chinese Journal of Nursing, 43, 47-49. (in Chinese)

[8] Murphy-Ende, K. (2001) Barriers to Palliative and Supportive Care. Nursing Clinics of North America, 36, 843-853.

[9] Syrjala, K.L., Abrams, J.R., Polissar, N.L., et al. (2008) Patient Training in Cancer Pain Management Using Integrated Print and Video Material a Multisite Randomized Controlled Trial. Pain, 135, 175-186.

https://doi.org/10.1016/j.pain.2007.10.026

Submit or recommend next manuscript to SCIRP and we will provide best service for you:

Accepting pre-submission inquiries through Email, Facebook, LinkedIn, Twitter, etc. A wide selection of journals (inclusive of 9 subjects, more than 200 journals) Providing 24-hour high-quality service User-friendly online submission system Fair and swift peer-review system Efficient typesetting and proofreading procedure Display of the result of downloads and visits, as well as the number of cited articles Maximum dissemination of your research work

Submit your manuscript at: http://papersubmission.scirp.org/

Or contact ojn@scirp.org 